\title{
Interesting Oriented Open Practical Teaching: Innovative Education Methods Exploration Marketing Specialty Practice Teaching
}

\author{
Yunxia Chi ${ }^{1}$, Lin Liu $^{2}$ \\ ${ }^{1}$ Department of Teaching Affairs, Hebei College of Industry and Technology, Shijiazhuang, China \\ ${ }^{2}$ Department of Economic Management, Shijiazhuang Tiedao University, Shijiazhuang, China
}

Email address:

chiyunxia11@126.com (Yunxia Chi)

To cite this article:

Yunxia Chi, Lin Liu. Interesting Oriented Open Practical Teaching: Innovative Education Methods Exploration Marketing Specialty Practice Teaching. Education Journal. Vol. 4, No. 5, 2015, pp. 290-293. doi: 10.11648/j.edu.20150405.25

\begin{abstract}
In the practical teaching process, according to the requirement of economy and society on talents, continuous innovation needs to be carried out on education methods so as to enhance the competitively of talents cultivated by higher vocational education. Interesting oriented open practice teaching well suited the psychological characteristics and behavior pattern of contemporary high vocational education students. Through a reasonable setting of program, content and assessment methods, open practice education has the advantage of strong self flexibility and respect for diversity of student characteristics, as well as the good adaptability to the demands of physical and mental development of students, and cultivation of their innovation capability.
\end{abstract}

Keywords: Interesting Orientation, Innovation Psychology, Open Practice Teaching

\section{Introduction}

On the two sessions this year, Prime Minister Li Keqiang raised an idea of "public entrepreneurship, public innovation" in his government work report. Innovation is the essence of the knowledge economy, a manifestation of the spirit of time, and an intrinsic factor to measure a country and nation's comprehensive strength and competitiveness. Innovative education is to meet the challenges of the knowledge economy era, taking fostering individuals' spirit and capability of innovation as the basic value orientation of education. Implementing innovative education in the field of higher vocational education has always been the focus of researchers. And many new ideas and new methods has been brought out, e.g., while developing in scale, vocational education should take personnel training of innovative spirit and ability as prerequisite, basis and specialty, and carry out innovative education with multi-hierarchy and pluralistic intelligence in vocational colleges. Innovation capability of teachers is a key factor of cultivating students' innovative ability. Researchers are also proposing a new practical teaching method for using innovative education, based on aspects like teaching philosophy, teaching contents, teaching methods and management, evaluation system. However, different specialties, different teaching contexts and social environments proposed different requirement for implementing practice teaching. These studies mainly stay in the theoretical stage. Whether it operates in practice or not, it still needs to be tested.

\section{Practical Teaching Demands Innovation of Teaching Methods}

Practical Teaching is not only essential to teaching in Higher Vocational Education, but also the most effective and direct way of implementing innovative education. In practical teaching step, traditional methods include internship, experiment, and practice. On the basis of traditional practice teaching, some researchers combined discussion, inquiry-based methods, designed and selected topics according to profession requirements, and guided students to actively conduct independent exploration, research and investigation activities, to find the appropriate principles or conclusions, and develop students' ability of innovate and creative thinking. Some good attempts have been taken. However, students' creative quality not only includes innovation capability, 
innovation sense, creative thinking, but also comprises innovative personality cultivation. Therefore, in the practical teaching process, it needs innovated new teaching methods according to requirement of the age on talents, in order to enhance the competitiveness of our educated talents.

\section{Interest-Oriented Open Practice Teaching}

The open practical teaching method is proposed and inspired by the open class in many countries around the world. Such learning method is called "informal education" in United Kingdom, "Freinet - Pacdagogik" in France, and "open education" in the United States. Open class learning allows the presence of any variation, allows appearance of new teaching ideas and curriculum thoughts, allows flexible schedules, allows teachers, students and all who participate in learning activities express their feelings and thinking in a real and unabashed manner, allows students to participate in the decision-making process of learning etc. The main objective of open class learning is to develop student's independence and decision skills, student's research and problem-solving skills. Through open classroom learning, students can achieve the self-determination ability, independence, evaluation and critique ability and creativity when they face the external environment and different things. Their self-confidence and communication skills can be improved, and they can form an open mindset without certain limitations of the program.

In many of our economics and management specialty practice teaching, we often encounter predicaments such as lack of space, shortage of teacher, and insufficiency of resources, and are unable to provide an ideal place for students to practice. Even if there are practical sites, only certain aspect of students' ability is developed. However, it is far from the requirement of society on our graduated talents. In the national level, it is clearly stated that the college's education reform should be deepened in the aspects of innovation and entrepreneurship, and focused on solving the outstanding problems in it. It should be got involved in the talents educating system, enriched curriculum, innovate teaching methods, enhanced teachers' qualification, promoted the close combination of teaching, research and practice, broken through the weakness of talent cultivation, and enhanced students' innovative spirit, entrepreneurial awareness and ability of innovation and entrepreneurship. Open classroom learning mode in foreign countries provides us with an idea, which is on the basis of reasonably setting practical teaching objectives, teaching content and assessment methods, we can use a wide range of social resources, to stimulates students' own initiative and creativity, arouse their interest in learning, and implementing open teaching, namely interesting-oriented open practical teaching. In the following, taking special market investigation in marketing as an example of our practical teaching.

Market special investigations by probing commodity market are to consolidate students' marketing and research knowledge, to understand their social and economic development reality. It can lay their the foundation for specialty course learning, and to better correlate the social reality and work practice in the future theory learning as well as deepen understanding and experience of specialty courses, and to train students' social skills, teamwork skills, capability of observing and understanding the society in the research process.

Usually, the market specialty investigation engages on the second semester of higher vocational college students' first year. College students at this time are roughly adapted to vocational education and life, and start to learn major courses and specialty fundamental courses. Students at this stage have the following psychological characteristics: they have certain independence and maverick value, rely less on others, have self-confidence, and are willingness to control and utilize environment in learning and life. They also have curiosity and thirst for knowledge, interest to pursue and explore, are able to take an open attitude towards the phenomena and things in external environment, learn skills to raise questions, and learn to actively express personal opinions and feelings. They have courage to bring ideas for realization, willingness to take risk, eagerness to engage in practical activities, desire to initiate and promote some action. They have keen awareness, and are able to respond to external stimuli in a timely manner; they have optimism self-evaluation, critical thinking skills, evaluation capability, ability to collect process and analyze information, and ability to realize the advantages and disadvantages of things. They would weigh and seize the key issues, seize the problem and effectively solve the problem, and finally evoke the interest to solve the problem. They can find a solution to the problem by constantly trying, are mentally prepared to compromise, and are good at cooperating with others. Based on the above vocational students' psychological characteristics, and then choosing the theme they are interested in as the research object, the usage of open teaching and practice can effectively cultivate students' innovative spirit, entrepreneurial awareness and ability of innovation and entrepreneurship.

\section{Composition and Structure of Open Practice Teaching}

Referring to the above point of view, the organization and implementation of the open teaching is divided into three stages: determining the research content and structure stage, organizing and performing study stage, communicating, summarizing and feedback stage.

Determination of research content and structure is the first stage of open practice teaching, which, in specific, includes forming the research team; determining the research topics; establishing the contact between students and subjects; analyzing the structure of the research topics, grabbing the whole picture of the topic and then decomposing and expanding the topics. The main tasks of this stage are:

1. Team personalized formation DIY. Students form their team freely according to their own preferences, if it is the 
first time to organize students to complete the task in a team pattern. It is preferred to let student's free combine first; if similar activities have been carried out already, then the teacher can arrange teams to increase the difficulty of teamwork and let the students have a preliminary understanding of teamwork before they go to their vocation, each team has members of 3 to 5 people. After the formation of each team, in order to further to develop the students' creativity, the students are required to design their own team name and create personalized business cards, which are required to fully show the elegance of the team members and the team features. This part is also included as part of practical assessment.

2. Research topics are raised and analyzed by the practical instructor's team and are allowed students to have a preliminary understanding of the range of topics for selection. Research topics are set closely to the actual economic life, and allows students to be operational, but with a certain degree of challenge. For example, we gave students topics such as Shijiazhuang foreign trade clothing store genuine investigation, Shijiazhuang Nansantiao luggage and bag market product quality survey, etc. these topics are not only close to the student life, but also closely related to their profession. Therefore, it is easy to stimulate the enthusiasm of students to participate.

Organization and implementation is the second phase of the open practice teaching, and is the key stage of the practice teaching. This stage is further divided into two smaller stages, the first of which is the selection and planning stage and the second being the implementation and completion of the research mission stage. Selection and planning are finished in the group range. The students select research topics according to their individual wishes, and their own interest. After the group initially identified the topics, the students are first required to review relevant information, and then further clarify the direction, and finally determine the research topics within the group, as well as talking about the development of the plan to complete the task, and making a clear division of labor for the task. Teachers, at this stage, first only give guiding opinions, and are responsible for inspection of their task process. As the reasonability of the plan, teachers can selectively make recommendations, intentionally let the students enhance their ability to deal with problems through setbacks and difficulties that may be encountered in practice, and furthermore improve their practical skills and social adaptability. Students can be allowed to take full charge of the implementation and completion of the research mission. Teachers can choose to supervise or not, but guidance and help should be guaranteed to the students once they need.

Opinion exchange, summarization and feedback stage is the final stage of the open practice teaching. The main task of this phase is to communicate and summarize the results of practice within the scope of group and class. Each research team briefs their own research tasks completing process, and their experience in the form of PPT presentation in class. Finally, students should have reflection of the arrangement for their own research process, the learning process, and the learning outcomes, etc., propose the methods to improve research, and accumulate experience for the future research and learning, so that students' ability to learn can be enhanced.

\section{Detailed implementation of Open Practice Teaching}

In the start-up stage of open practice teaching, teacher should be teaching all students. In order to ensure the smooth implementation of the latter part of the research, in the start-up stage, we usually need to clarify the purpose, arrangements and requirements of the practice teaching, to analyze the proposed research topic, and to provide guidance and advice to the students on selecting their topics. Particularly, teachers should counsel the students on how to well fulfill their research mission, answer their various problems and offer some suggestions on issues that may arise, in order to ensure the safety of the late implementation. At this stage, the teacher's role is very important, and adequate preparations are needed.

In the stage of detailed implementation of practice teaching, students possess very prominent role, this process is the active learning process of each individual student. Activities ranging from the selection of specific topics to the development of specific research program, the implementation of research activities, the inspection of the study results and the final reflection are all independent process for students. Through independent individual work, plus panel discussion and communication through the whole class, students can not only fully grasp the knowledge of a particular topic or specialty, but also learn to collaborate between teammates. Personal independence and students' communication skills are stressed. At this stage, teachers counsel students on their selection of topics, review their research plan, guide and supervise the whole process of the research; the students take fully in charge, while teachers give full range of guidance.

Giving students necessary feedback and evaluation is an essential part for the open practice teaching. After the investigation, the students need to conduct research results report and analysis within group and class, in order to improve students' self-judgment, good communication skills, information technology ability and learning ability. Teachers and other students are free to raise questions based on each group's report, and to discuss issues of doubt and interest, while according to students' plan notes, research process and results, etc., teachers will need to make remarks, give suggestions, and provide students with appropriate guidance.

A reasonable assessment system is indispensable to the effective development of open practice teaching. Teachers can set the assessment criteria according to the assignment and task performance. In the investigation of the foreign trade in International Economics and Trade, we setup six target; DIY team design, research prospectus, written research report, research result exchange, teamwork and 
evaluation report. DIY team design is to assess the creative ability of students; Research prospectus and written research report are the reflections of students' ability of self-determination and independence. To develop students' creativity and self-confidence; the exchange of research result aims at improving self-confidence and students' ability to evaluate and critique; Teamwork is focus on the training of communicative ability and collaboration consciousness. Evaluation report is a self-assessment report which the students are required to submit after the group has finished the panel report and teacher reviews, where students make summary of their research, identify deficiencies, propose improvements, in order to improve the student's ability to solve problems, self-evaluation and learning ability.

\section{The Evaluation of Open Practice Teaching}

Open practice teaching was imitated from the foreign open classroom studying and carrying out in the practice field. After the explore on the basic courses, professional training courses, internship and practice education in both Economics and Management specialty in recent years, we believe that it is the teaching method that conform to the psychological feature, behavior patterns and characteristics of vocational college students. It is flexible and attention to the different personality of students. Meeting the needs from the physical and mental development and promote psychosomatic development.

From the view of teaching, the open practice teaching combines students with society, so that students have a more specific and fully social cognition, know the information that has the feeling of the era, and learn the knowledge and experience that is related to their life. To achieve the goal of practical teaching, in the meantime, improve students' ability of self-determination, participation and teamwork, developing the choice-making ability and cognitive ability. It has a significant effect on the improving of students' social adaptability, learning and creativity ability. The process not only takes care of the transfer of knowledge, but also pay attention to the students 'enthusiasm and initiative. Playing the role of teachers in teaching while handing the learning initiative to the students can maximize the effect of teaching in the process of students' development and gain better results for the practical teaching.

From the students' point of view, the open practice teaching provides students with an open learning environment and learning space, they have the opportunity to take advantage of the favorable conditions, gradually worked out the most suitable learning methods and study skills and master the best learning strategies. It has been testified in the summary of students' reports.

Students generally believed that the research gives full play to their self-motivation and learned to get along with others, exchange and communication. They also learned that the more perspectives they seek out, the more they push the boundaries of their mind. Students start to self-study and gain more self-confidence.

Overall, students prefer the form and effect of the special investigation, and find it great rewarding. In thematic research practices, students were helped to consolidate what they have learnt and get to know some new specialized knowledge through lectures and research, while expand their horizon ; Students' practical ability was improved by hands-on experience; By encouraging students to freely combination, advocating personality of DIY concept on group organization and selecting the topic of interest from intrigued marketing subject, it also stimulates the self-motivation, innovation ability and ability to work as a team for students. Throughout the process, students master a certain research methods and research techniques, enhance the teamwork spirit and improve their ability to identify and resolve problems. It is particularly important that students found out their knowledge unstable and stretched in practice, and realize that there are many differences between theory and reality. It lays the emotional foundation in special course studying for students and is convenient for carrying out the teaching activities.

\section{References}

[1] Shen Jiahua. Review on Innovation Education in the Higher Vocational Education [J]. Higher Education Research, 2005(31).

[2] Xiong Wei, Kang Gang. On Innovation Education Application in Higher Vocational Education [J]. Education and Vocation, 2005 (18).

[3] Miao NInling. Study on Teacher's Innovation Competence in Higher Vocational Colleges [J]. Journal of Changzhou Vocation College of Information Technology, 2005(1).

[4] Zhang Xin, Chai Ying. Practical Teaching Mode Applied in the Innovation Education $[\mathrm{J}]$. Journal of Liaoning Administration College.

[5] Zhong Qiquan. Inquiry Study in Global View[M]. Shanghai: Shanghai Education Press, 2003.

[6] Wu Yingiian. Higher Vocational Colleges Innovation talents Research [D]. Fudan University, 2012: 5.

[7] $\mathrm{Xu}$ Wenhai, Caojing. Higher Vocational Colleges Entrepreneurship Education Research[J]. Education Theory and Practice, 2014 (33): 28-29.

[8] Wang Haocheng. Based on Engineering Innovation Education Practical Teaching System Research[J]. Laboratory Research and Probe, 2014(33): 28-29.

[9] Zhong Qiquan. Inquiry Study in Global Perspective[M]. Shanghai Education Press, 2003. 12.

[10] Zhang Qiaoying. Higher Vocational Education Practical Teaching Assessment Research[D]. Henan University, 2013: 3. 